\title{
UNA VISIÓN COGNITIVA DEL SISTEMA TEMPORAL Y MODAL DEL VERBO EN ESPAÑOL
}

\author{
Alejandro Castañeua Castro \\ Universidad de Granada \\ Departamento de Lingüística General \\ acastro@ugr.es
}

\begin{abstract}
Resumen
Our aim is to explore a cognitive account of the Spanish verb temporal and modal system based on some of the concepts stated in Langacker's Cognitive Grammar model. On the one hand, our proposal rests on concepts like epistemic model, grounding functions, profile and base of expressions' meaning, and scope of predication. These concepts and constructs are applied to describe, in a general insight, the main Spanish verb modal and temporal oppositions. On the other hand, the different kinds of catcgorization links (extension and elaboration) proposed by Langacker will allow us to find a promising way to overcome the discussion about the role of temporality in the description of the Spanish verbal system.

Rudolf Steiner [...] hace corresponder la mera estadia inerte de los minerales con la del hombre muerta; la furtiva y silenciosa de las plantas con la del hombre que duerme, la solamente actual y olvidadiza de los animales con la del hombre que sueña. [...] Dueño de esas tres jerarquias es, según Rudolf Steinter, el hombre, que además tiene el yo: vale decir la memoria de lo pasado y la previsión de lo porvenir, vale decir, el tiempo.
\end{abstract}

Borges (1992: 227)

\section{Modelo Episiémico}

En el presente artículo pretendemos esbozar una aproximación a las categorías de tiempo y modo del verbo español basada fundamentalmente en el concepto de modeto epistémico elaborado (elaborated epistemic model) desarrollado por Langacker (1991: 240-249) y aplicado por cste autor en la descripción de algunos aspectos del sistema temporal y modal del inglés.

Con el modelo epistémico elaborado Langacker articula un modelo cognitivo idealizado que da cuenta de los distintos ámbitos epistémicos que configuran la representación de la realidad y su devenir a través del tiempo, tal y como la construye el sujeto conceptualizador. Se trata de un modelo de carácter espacial que reproducimos aquí en la figura 1. 
Figura 1. Espacios en el mundo representado por el sujeto conceptualizador.

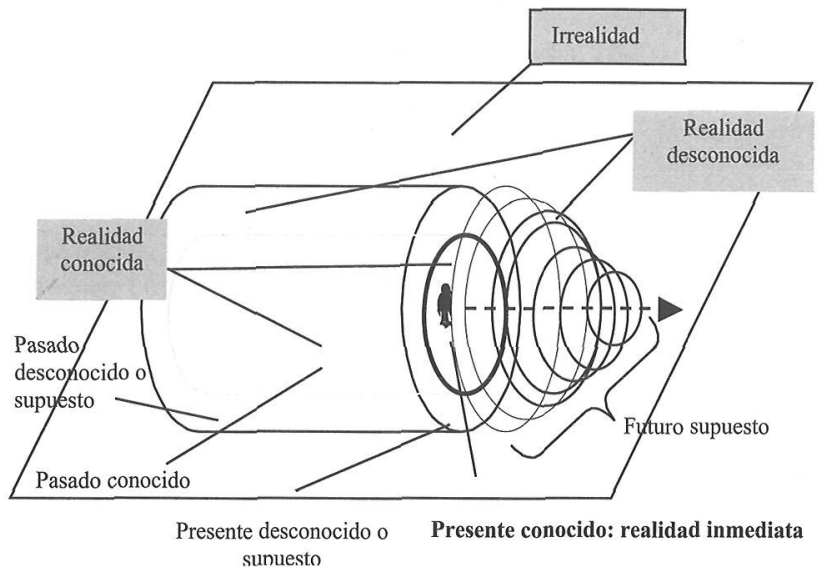

En las precisas y clarificadoras palabras de Langacker (ibid.: 242-243):

[...] Its essential notion is that certain situations (or «states of affairs») are accepted by a particular conceptualizer $(\mathrm{C})$ as being real, whereas others are not. Collectively, the situations accorded that status constitutes C's conception of known reality [...]. Reality is neither simple nor static, but an ever-evolving entity whose evolution continuously augments the complexity of the structure already defined by its previous history: the cylinder depicting it should be imagined as «growing» along the axis indicated by the arrow. The leading edge of this expanding structure (i. e. the face of the cylinder) is termed immediate reality. It is from this vantage point - from reality at the latest stage of its evolution - that $\mathrm{C}$ views and he has direct perceptual access only to portions of this region. Irreality comprises everything other than (known) reality. It is important to bear in mind that a situation does not belong to reality or irreality on the basis of how the world has actually evolved, but depends instead on whether the conceptualizer knows and accepts it as being part of that evolutionary sequence.

Estos elementos constituyen lo que Langacker llama modelo epistémico básico. Otras distinciones permiten completar la noción de modelo epistémico elaborado. Siguiendo de la mano de Langacker (ibid.: 243):

[...] To the basic epistemic model, it adds the conceptualizer's realization that reality as he knows it is not exhaustive of the world and its evolutionary history. The core for known reality is thus surrounded by a much larger region of unknown reality $[\ldots]$

En la figura 1, además de los ámbitos epistémicos (realidad conocida inmediata, realidad conocida, realidad desconocida e irrealidad), incluimos la correspondencia de las distintas regiones epistémicamente relevantes, tal y como las explica Langacker, con las demarca- 
ciones relevantes desde el punto de vista de la dimensión temporal. En este sentido, hay que aclarar que el futuro queda equiparado epistémicamente a la rcalidad desconocida. El cilindro exterior, más abarcador, constituido por situaciones previstas, probables o supuestas, pero de las que no tenemos evidencia directa, se proyecta hacia el futuro en la medida en que el estado actual y la dirección impuesta por la historia acumulada hasta el presente permite prever también la dirección probable de su evolución posterior. Los discos concéntricos que van reduciendo su extensión cónicamente conforme se distancian del momento presente, representan la reducción de la región que puede preverse conforme nos alcjamos de la actualidad.

Por otra parte, tanto el presente (el corte transversal correspondiente al extremo del cilindro) como el pasado (todo el volumen de cortes transversales acumulados hasta el presente) quedan subdivididos en dos regiones distintas: en cuanto al presente, se distingue, por un lado, el presente que se corresponde a la realidad inmediatamente conocida, cs decir, accesible directamente desde la posición que ocupa el sujeto que concibe y habla y, por otro, el presente supuesto, correspondiente a todas aquellas situaciones que, aun siendo dadas por reales, no son accesibles más que indirectamente a partir de procesos inferenciales o fucntes indirectas. En cuanto al pasado, también cabe hacer la distinción entre el pasado conocido, experimentado, y el pasado desconocido o supuesto. De estc modo la experiencia de la dimensión del tiempo queda incorporada, también siguiendo la propuesta de Langacker, al modelo epistémico que le sirve de basc.

\section{MODOS DEL VERBO ESPAÑOL}

\subsection{Indicativo y condicionado}

Esta aproximación al modelo epistémico permite ya intuir una primera relación fructifera con cl sistema temporal modal del verbo en español. La realidad conocida y la realidad supuesta se corresponderían, respectivamente, con los ámbitos de actualización del indicativo (cantas para el presente, cantabas para el pasado) y del condicionado (cantarás para el presente y cantarías para el pasado), según denominación de Alarcos (1994: 152-155). El llamado futuro, respecto del punto de vista anclado en el presente, y el condicional, respecto del pasado, se aplicarían a la localización en el ámbito epistémico de la realidad supucsta, tanto coetánea al punto de refercncia como proyectada en estados posteriores previstos. Así se observa en (1)- (4):

(1) Supongo que Maria cantará muy bien porque todos sus hermanos también to hacen.

(2) Supongo que esta niña cantará muy bien cuando sea mayor.

(3) Supongo que Maria cantaria muy bien porque todos sus hermanos también lo hacian.

(4) Supongo que aquella niña cantaría muy bien cuando fuera mayor.

El origen perifrástico del futuro y su correlato en el pasado, el condicional, a partir de la combinación de haber, en el sentido de 'tener que', con el infinitivo del verbo en cuestión, avala esta equiparación epistémica de los usos referidos al porvenir y los relacionados con la suposición de hechos contemporáneos no controlados. 


\subsection{Subjuntivo}

Los ámbitos de la realidad conocida y la realidad desconocida quedan, por tanto, asociados respectivamente a los modos indicativo y condicionado. Pero, ¿qué ocurre con cl modo subjuntivo? Este modo se opone a los otros dos en relación a uma dimensión distinta a las consideradas hasta ahora y que está vinculada a la actualización. Creemos que también puede ser fructífero aquí otro par de distinciones básicas propuestas por Langacker. Se trata, por una parte, de algunas de las nociones que aplica en su explicación de la actualización nominal y verbal, $y$, por otra, de la distinción, esencial en su teoría gramatical, entre perfil y base.

\subsubsection{Perfil y base}

La importancia que en nuestra opinión reviste la distinción entre perfil y base para la caracterización del subjuntivo requiere que comentemos estas nociones fundamentales en el modelo de Langacker. Según la concepción de este autor (1987: 183-189), en el significado de las expresiones conviene distinguir el perfil, lo propiamente designado por la expresión, de la base, el ámbito dimensional y rclacional que sirve de fondo (necesariamente presupuesto) a tal designación.

Por ejemplo, un conjunto de puntos se considera una línea recta si atendemos a la disposición ordenada de unos puntos respecto de otros y tomamos como base exclusivamente el espacio no ordenado inmediato, pero ese mismo conjunto de puntos puede ser un radio si se considera como base el ámbito mayor de la circunferencia de la que puede formar parte. Asimismo, un ángulo, en el ámbito de un objeto tridimensional en el que se localiza, puede concebirse como rincón, en referencia a su lado cóncavo, es decir, tomando como base el espacio interior del objeto, o como esquina, en referencia a su lado convexo, es decir, tomando como base el espacio externo circundante al objeto. La familia es la base sobre la que se designan relaciones de parentesco como tio, abuelo o hermano; la mano es la base respecto de la cual se designa un dedo. Igualmente, el perfil de la preposición desde es el límite inicial de un recorrido y su base el espacio cuyo límite inicial designa dicha preposición. Por su parte, hasta designa el límite final del espacio que se recorre y que constituye su base.

Las expresiones pueden distinguirse entre sí por configurar dos imágenes distintas de una misma situación objetiva más quc por representar dos situaciones objetivas distintas. Precisamente una de las maneras en que se configuran distintas reresentaciones o percepciones lingüisticas de una misma situación o de un mismo modelo cognitivo es mediante la elección de unos aspectos y no otros como perfil o como base. De este modo, desde y hasta remiten a un mismo modelo o situación esquemática: la del espacio abarcado por el límite inicial y final de un recorrido. Ahora bien, mientras que desde escoge como perfil el límite inicial relcgando el resto de elementos (entre ellos el límite final) a la base, hasta selecciona

Figura 2
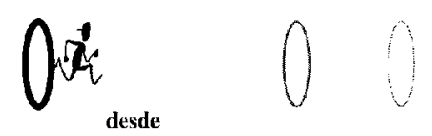

hasta

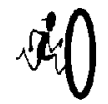


como perfil el límite final relegando el resto de elementos (entre ellos el límite inicial) a la base. Así se pretende hacer ver en la figura 2.

\subsubsection{Perfil y base en la determinación nominal}

Langacker (1991: 92) llama la atención sobre el hecho de que los elementos determinantes (artículos o demostrativos, por cjcmplo) que sirven a la función de apuntar, en el dominio de actualización pertinente, a un ejemplar (o conjunto de ejemplares) de cntre todos los que cumplen las especificaciones de un tipo, pueden describirse como morfemas en cuyo significado el perfil se corresponde con cl caso ejemplar designado, y la base con la evocación genérica tanto de un tipo como del conjunto indeterminado del resto de cjemplares localizables en el dominio de actualización y que cumplen las especificaciones del tipo. En la figura 3 se representa esta idea distinguicndo entre elementos dibujados con trazo continuo y grueso (perfil) de los elementos dibujados con trazo menos grueso y discontinuo (base).

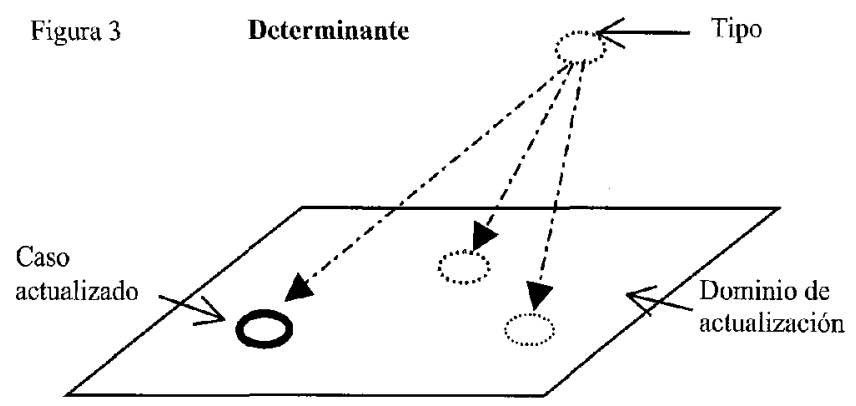

El significado genérico de un nombre no determinado sc correspondería con los mismos elementos pero en una configuración perfil/base distinta. En este caso el perfil lo constituiría el tipo, mientras que la base estaría formada por el conjunto de ejemplares localizables en el dominio de actualización pertinente. Esta configuración semántica se representa en la figura 4.

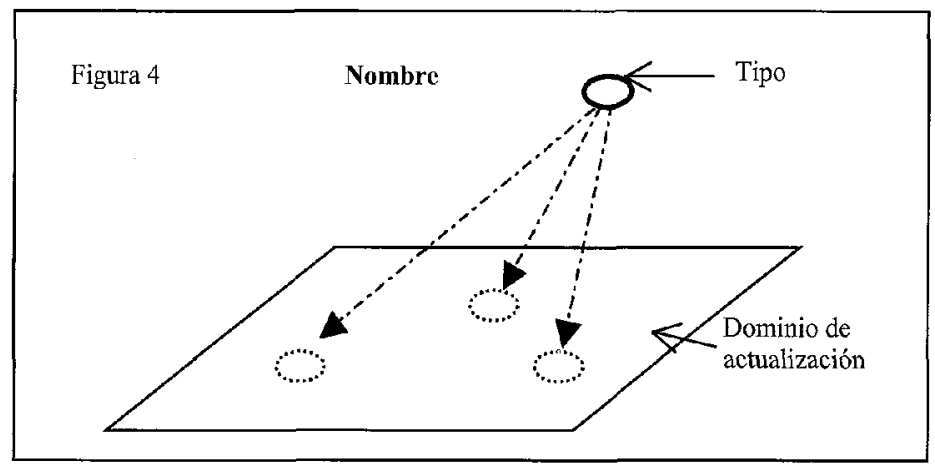




\subsubsection{Perfil y base en el subjuntivo}

En nuestra opinión, la distinción entre los modos indicativo y condicionado, por un lado, y el modo subjuntivo, por otro, puede explicarse en términos parecidos a los expuestos respecto a detcrminantes y nombres. Mientras que el contenido lexemático del verbo designa el proceso tipo, los morfemas modales de indicativo y condicionado localizarían en los dominios de actualización correspondientes (realidad conocida cn cl caso del indicativo y realidad supuesta en el caso del condicionado) casos o ejemplares que cumplirían las especificaciones del proceso tipo. Por su parte, los morfemas modales de subjuntivo designarian, en tanto que perfil, un proceso tipo y no, como hacen indicativo y condicionado, casos localizados en distintos ámbitos epistémicos. No obstante, a diferencia de las formas no personales, en particular del infinitivo, los morfemas de subjuntivo incluirían en su significado, como base de su valor, la proyección potencial al ámbito del presente o del pasado. Esta idea se resume gráficamente en las figuras 5(a) y 5(b). Los trazos en zigzag representan procesos.

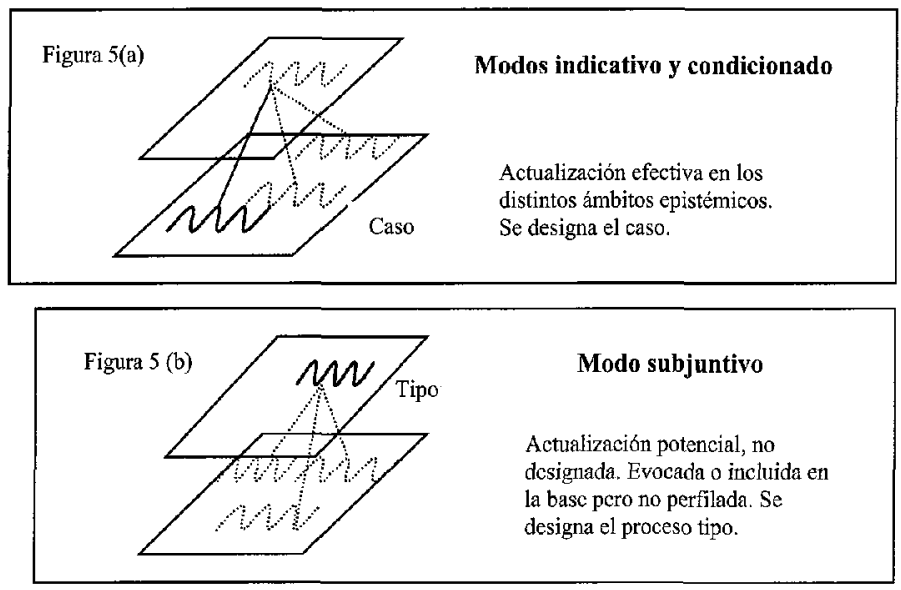

\subsubsection{Subjuntivo presente y subjuntivo pasado}

El modo subjuntivo comparte no pocos comportamientos distribucionales con el infinitivo. Destaca el hecho de que scan formas circunscritas al ámbito de la subordinación. La localización efectiva en el ámbito epistémico correspondiente que llevan a cabo indicativo y condicionado los capacita para la constitución de enunciados con núcleo verbal independicntcs, mientras que el infinitivo y el subjuntivo, precisamente porque no representan actualización, no pueden otorgar carácter independiente a una cláusula. Por otra parte, la capacidad de enunciar declarativamente no parece corresponder a la idca de ticmpo sino a la de modo, pues la distinción temporal - aunque como ámbito de proyección potencial-, está presente en los morfemas de subjuntivo. Ésta es precisamente, en nuestra opinión, la principal diferencia con el infinitivo, pues esta forma designa un proceso sin evocar, como 

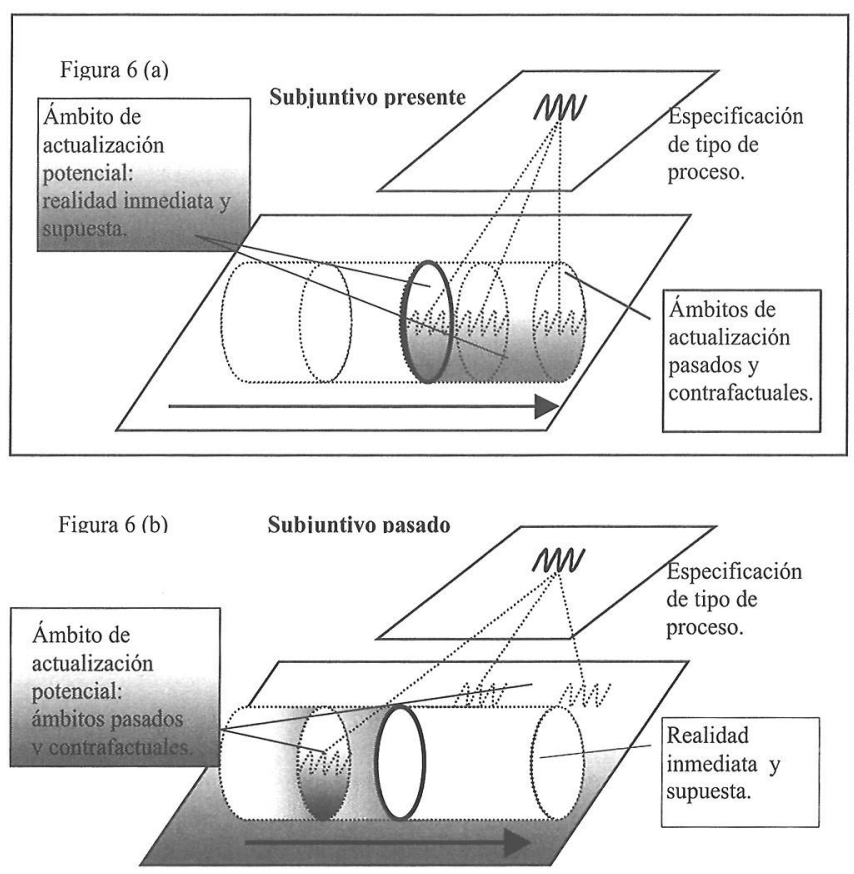

base, los ámbitos temporales de actualización. La representación gráfica de esta idea se intenta en la figuras $6(\mathrm{a})$ y $6(\mathrm{~b})$ para la distinción entre subjuntivo presente y subjuntivo pasado.

\subsubsection{Subjuntivo e irrealidad}

La aproximación esbozada permite dar cuenta de los valores concretos de los que se reviste el subjuntivo. El contenido proposicional que se presenta en subjuntivo queda en suspenso desde el punto de vista discursivo. Si indicativo y condicionado realizan una actualización efectiva, poniendo, si aplicamos la metáfora del ajedrez, fichas en las distintas regiones del tablero epistémico que comparten los interlocutores, el subjuntivo permite apuntar a una región o una posición y manejar el contenido proposicional como un contenido virtual, pero no cuenta como un movimiento, como una posición asumida por el interlocutor. Es como si cogiéramos una ficha (la idea de un proceso especificado en ciertos aspectos) y probáramos a colocarla en alguna nueva posición, por ejemplo para representarnos mejor sus eventuales consecuencias, pero sin llegar a soltarla y sin pulsar el cronómetro. Ello nos permite mencionar o aludir a contenidos proposicionales sin hacernos responsables de su actualización. De ahí que el subjuntivo aparezca en contextos que tienen en común, como señala Ruiz Campillo (1998: 62), la falta de asunción declarativa por parte del ha- 
blante. Precisamente la capacidad declarativa es lo que permite que los modos indicativo y condicionado sean distinguidos del subjuntivo. ${ }^{1}$

Es importante aclarar dos aspectos en relación con esta aproximación al subjuntivo.

En primer lugar, el subjuntivo no debe confundirse con la ncgación de realidad. El carácter de irrcal o virtual del modo subjuntivo es aceptable sólo en la medida en que se entienda como ausencia de compromiso sobre la correspondencia con la realidad del contenido predicativo, lo cual no significa negación de esa correspondencia. Simplemente el subjunlivo no tiene en cuenta el valor de verdad de los contenidos predicativos a los que se adjunta. Eso explica la posibilidad de que usemos subjuntivo para hacer mención de contenidos predicativos que damos por supuestos y sobre los que queremos hacer algún tipo de valoración (Me gusta que, siempre que me ve, me haga cumplidos) pero también para los que son objeto de nuestra voluntad (Prefiero que te quedes), los que planteamos como posibilidades sin confirmar (Aunque me despidan voy a decirselo), etc. El hecho de que en contextos como los de (5)- (8) el subjuntivo sc interprete como signo de irrealidad $o$ incertidumbre es consecuencia de procesos inferenciales.

(5) Las niñas, ya porque tuvieran prisa ya porque no me conocian, no se despidieron de mí.

(6) El locutor, bien porque le diera vergüenza estar ante las cámaras bien porque no se sabía el guión, se levantó de su sillón.

(7) Aunque se enfade voy a decírselo. Creo que es mejor.

(8) Como esté enfadado no nos va a dejar cntrar.

En todos estos casos la idea de ausencia de correspondencia con la realidad de los procesos conjugados en subjuntivo se deriva de una implicatura generalizada de cantidad (Grice, 1975: 528-529) que adopta la siguiente forma: si se diera el caso de que algo pudiera afirmarse lo afirmaríamos con cl indicativo, forma con la que, específicamente y explícitamente, se declara el valor de verdad de algo. $\mathrm{Si}$, disponiendo de esa forma más explícita, acudimos a una más vaga, menos comprometida, mcnos informativa, damos a entender que no se dan las condiciones para usar el indicativo y, por tanto, que el hecho al que aludimos no es más que una proposición meramente concebida no coincidente con la realidad, una representación meramente virtual de un hecho. Esto es lo que sucede en las oraciones (5)-(8). Sin embargo, la falta de correspondencia con la realidad no es más que una implicatura, un producto de procesos inferenciales que dependen de la información contextual. Obsérvense, en rclación con ello, los ejemplos (9)-(11).

1 Esta idea nos permite concebir la posibilidad de un nivel funcional más, aparte de los propuestos por Langacker en la deteminación del contenido verbal cuando distingue (1991: 421-423) la instanciación de un tipo (su especificación mediante modificadores y complementos), de su cuantificación (aspecto y voz) y de su actualización (grounding) (ticmpo y modo). En este último nivel (grounding), Langacker sitúa la acción de la determinación temporal-modal, que concibe como una función compleja indivisiblc. En nuestra opinión, la existencia, en lenguas como el español, del modo subjuntivo permite establecer dentro del nivel de la actualización (grounding) una nueva distinción cntre «temporalización» y «modalización». En rigor, la posibilidad de temporalizar un proceso sin llevar a cabo su localización efectiva en algún ámbito cpistémico (realidad conocida o realidad desconocida o supuesta) permite concebir un tercera categoria de carácter relacional complejo: además de las de proceso (formas finitas del verbo) y relación compleja atemporal (formas no finitas), se dispondría de una tercera categoria, la de los procesos no modalizados, es decir, la correspondiente a las formas finitas temporalizadas no localizadas efectivamente en ningún ámbito epistémico: las formas de subjuntivo. 
(9) Que compartáis intereses será una ventaja.

(10) No me importa que me no me llamen.

(11) Aunque me despidan voy a decirlo.

Las expresioncs que compartáis intereses, que no me llamen, me despidan son compatibles tanto con la irrealidad como con la realidad de las situaciones a las que se refieren, tal y como se observa, respectivamente, en los contextos 9(b)-11(b) y $9(\mathrm{c})-11$ (c):

(9b) Que compartáis intereses, si finalmente los compartís, será una ventaja.

(10b) No me importa que me no me llamen. En realidad ya me han dicho que no me van llamar y estoy tan tranquilo.

(11b) Aunque me despidan, que no tiene por qué pasar, voy a decirlo.

(9c) Que compartáis intereses, y eso es lo que tú me has confirmado ahora, será una ventaja.

(10c) No me importa que me no me llamcn. Además, todavia pueden llamarme.

(11c) Aunque me despidan ahora - ya me lo han comunicado-, voy a decirlo.

Por otra parte, que el subjuntivo no se identifique como tal con la irrealidad no significa que la noción de irrealidad no sea relevante epistémicamente. En el modelo epistémico de Langacker lo es: se localiza en el espacio vacío que rodea tanto a la realidad como a la proyección futura de la realidad (vid. figura 1.). Es el espacio que corresponde a la contrafactualidad, a los mundos imaginados o ficticios. Más adelante abordarcmos la manera en que los morfemas temporal-modales son usados en relación con este espacio epistémico.

\section{TIEMPOS COMPUESTOS}

La matriz que se deriva del cruce entre los tres modos y los dos espacios temporales nos permite ya localizar seis de las siete formas simples del sistema verbal español, como se ve en la Tabla 1.

\begin{tabular}{|c|c|c|c|}
\hline Tabla 1 & Indicativo & Condicionado & Subuntivo \\
\hline PRESENTE & cantas & cantarás & cantes \\
\hline Pasado & cantabas & cantarias & cantaras \\
\hline
\end{tabular}

Quedan por integrar en el conjunto los tiempos compuestos y el indefinido.

Los tiempos compuestos reciben atención especial de Langacker a través de su análisis del present perfect del inglés (1991: 220-225), aplicable en gran medida al caso del español. Sobre estas formas compuestas diremos que muestran dos facetas: por un lado aluden a procesos terminados y por otro a la relación de vigencia o relevancia de esa terminación en un ámbito epistémico determinado: presente en el caso del pretérito perfecto (has / habrás / hayas cantado) y pasado cn cl caso del pluscuamperfecto (habias cantado / habrías cantado / hubieras cantado). Es una forma perifrástica de expresar conjuntamente nocioncs aspectuales y temporales. Se trata de una construcción 
gramatical $^{2}$ que enriquece las posibilidades funcionales del sistema al permitir desvincular la relación temporal de anterioridad, que logra expresarse mediante el carácter terminativo de la forma de participio, de la noción epistémica de realidad pasada o no actual frente a la de realidad presente 0 actual. En cfccto, el pretérito perfecto, por ejemplo, permite localizar un evento concluido en el ámbito de la realidad presente. Igualmente, el pluscuamperfecto permite aludir a hechos terminados en relación con una ćpoca pasada. Como consecuenciá, se ve facilitada la reconstrucción de mundos narrados independientes del presente, puesto que las relaciones temporales expresadas, por una partc, a través de las formas compuestas en relación con las simples (anterioridad) y, por otra, mediante las formas condicionadas en relación con las de indicativo (posterioridad) permiten reconstruir mundos complejos configurados en torno no sólo a espacios epistémicos (realidad conocida / realidad supuesta), sino también respecto a una dimensión temporal propia (anterioridad / posterioridad).

\section{INDEFINIDO}

\subsection{Aproximación aspectual}

Falta, para completar la nómina de las formas que se consideran constitutivas del sistema verbal español actual, comentar el indefinido (canté) y la mancra en que encaja en este sistema. Para empezar, creemos que su distinción del resto de las formas simples, como apunta Ruiz Campillo (1998: 150), es de carácter aspectual, pues se trata del único tiempo que representa un proceso como realizado completamente. El hecho de que, a diferencia de los perfectos, no tenga carácter perifrástico, sino que se trate de una auténtica forma de actualización epistémica, nos remite necesariamente al momento actual como punto de referencia obligado respecto del cual entendemos la terminación del hecho. Eso parece descartar al indefinido en los usos contrafactuales, a diferencia del resto de las formas simples y compuestas.

En relación con las formas simples imperfectivas de pasado, en particular, en relación con el imperfecto (cantaba), entendemos, de acuerdo con Alarcos (1994: 160-164) que esta oposición es de carácter aspectual: indefinido, terminativo / impcrfccto, no tcrminativo. Uno de los argumentos más recurrentes que se han aducido contra la concepción aspectual de la oposición imperfecto / indefinido es el basado en los casos en que el imperfecto aparece con verbos que aluden a acciones que no pueden darse sino como terminadas. Esta circunstancia se da en el, así llamado, «imperfecto periodístico», como ilustran los ejemplos (12) y (13):

(12) E1 tren llegaba a las tres y tres en punto.

(13) En el último minuto Alfonso marcaba el gol de la victoria y de la clasificación.

2 No olvidemos que la construcción de perfecto no es propiamente hablando un ticmpo verbal. Bastc tener en cuenta la existencia de expresiones como haber cantado. Lo que se actualiza en las formas compuestas es la relación no terminativa que contrae la terminación de cierto proceso con delerminado ámbito epistémico temporal y que se expresa en la construcción haber + participio. 
Si el imperfecto es 'no terminativo', ¿cómo pueden darse ejemplos como los anteriores? En Castañeda y Ortega (2001: 224) se responde a esta objeción contra la concepción aspectual:

Se da una confusión muy frecuente en la conccpción de ésta y otras oposiciones estructurales de carácter privativo, caracterizadas por la presencia, en uno de los miembros opuestos, de cierto rasgo distintivo, ausente en el otro miembro. Se entiende, equivocadamente, que el término 'no marcado' de la oposición está caracterizado positivamente: si el indefinido expresa 'término' o carácter 'perfectivo' de la acción, el imperfecto cxpresa 'continuidad', 'no término' o carácter 'imperfectivo' de la acción. Sin embargo, la oposición a la que nos referimos es privativa y no, como denota la concepción errónea mencionada, equipolente. Es decir, en ella, como en tantas otras, en el término 'no marcado' no está presente el rasgo en cuestión. Así, el imperfecto, a diferencia del indefinido, no informa sobre el 'término' de la predicación, lo que -conviene resaltarlo- no significa que exprese explícitamente su 'continuidad' o su 'no término'. En suma, esta forma temporal no se halla especificada en tal sentido. Es cierto que normalmente el imperfecto se entiende como falta de 'término', como 'continuidad' o 'vigencia' de una acción, estado o proceso dado, pero esa interpretación es un efecto de sentido [...]. Dicho efecto surge cn virtud del siguiente razonamiento: puesto que existe a disposición del hablante una forma temporal, el indefinido, que expresa explícita o inequivocamente el 'término' de la acción, estado o proceso, si fuera el caso de que la acción quisiera expresarse como terminadi, se habría escogido esta forma verbal, que cs la más informativa al respecto. Si en las mismas circunstancias se estuviera utilizando el impcrfecto, se estaría contraviniendo la máxima de cantidad. Ahora bien, desde un punto de vista estrictamente semántico, nada en la carga semántica del imperfecto impide que éste sea compatible con acciones, estados o procesos que se den por concluidos. Por ello es posible, para ciertos contextos en los que se cancele la implicación anterior, usar el imperfecto para referirse a hechos que sólo pueden interpretarse como concluidos o realizados completamente.»

\subsection{Alcance designativo en la oposición indefinido / imperfecto}

Lo que desde el punto de vista estructural-funcional se entiende como una oposición privativa (un término de la oposición posee todos los rasgos que definen al otro término y otros más que no compartc con éste) creemos que puede entenderse desdc la perspectiva de la Gramática Cognitiva como un problema de mayor o menor abarque o alcance en la designación alternativa que caracteriza a una u otra forma de representar un proceso. La idea clave es considerar que indefinido e impcrfecto constituyen dos percepciones alternativas de un mismo proceso. En ambos casos presuponemos un modelo cognitivo sobre la forma en que los distintos tipos de procesos se generan, se desarrollan y concluyen. Pues bicn, cada morfema temporal proyecta una imagen distinta de esa concepción compleja que poseemos de los procesos: mientras que el indefinido representa una visión distante o panorámica que abarca el principio, el desarrollo y el término del proceso, el imperfecto representa una visión fragmentaria o menos abarcadora que no incluye la represcntación del término o la conclusión del proceso ${ }^{3}$.

3 Ruiz Campillo (1998: 200) aplica las nocioncs perceptivas de «visión interion» y «visión exterior» de un suceso para caracterizar respectivamente al imperfecto y al indefinido. 
Figura 7

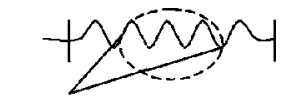

cantaba

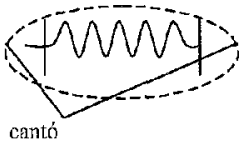

Siguiendo algunas de las convenciones adoptadas por Langacker para explicar la distinción entre representaciones imperfectivas y perfectivas y que él aplica a la distinción de la construcción progresiva frente a las no progresivas en inglés, representamos tales imágenes alternativas en la figura 7 .

Ahora bien, como ya hemos señalado respecto de la oposición subjuntivo / indicativo, hacer abstracción del término de un proceso, no designarlo explícitamente, no supone necesariamente negarlo. De igual manera, si digo la puerla se ha cerrado puedo dar a entender que ha ocurrido sin la intervención de nadie, pero no hacer referencia a un agente no significa, estrictamente hablando, que descartc su presencia. Esa es sólo una de las posibilidades: puede que considere que no ha intervenido nadie (la puerta se ha cerrado sola), puede que tenga presente que ha intervenido alguien pero no quiero mencionarlo, o puede que suponga que ha intervenido alguna persona pero no he podido percibir su intervención (he visto cómo se cierra una puerta desde fuera pero no a la persona que lo ha hecho). Esta situación es semejante a la de los ejemplos (12) y (13): en ellos, al usar imperfecto, no se hace mención del término, no sc designa, no se ilumina lingüisticamente, por así dccirlo, pero eso no significa su negación.

Por otra parte, conviene resaltar que, en el marco de una narración (una historia que estamos desgranando para nuestro interlocutor tal y como se desarrolló en su proceso pero que nosotros controlamos en sus resultados finales), expresar un hecho sin indicar su término es una opción marcada discursivamente. En efecto, si después de sucedido, informáramos de un hecho sin dar cuenta de su final, si priváramos al intcrlocutor de esa perspectiva más completa, ello sólo lo justificaría el que el hecho no llegó a concluirse o el que el hecho concebido en su desarrollo se establece como mareo en relación con el cual situamos otro4.

(14) Cuando pagaba los billetes oí el móvil en la cartera.

\section{Pasado y contrafactualidai)}

Una cuestión que adquiere la mayor importancia a la hora de decidirse por una forma $u$ otra de concebir el sistema verbal es el modo en que cada alternativa da cuenta de los usos de las formas de pasado para hacer referencia a situaciones irreales, hipotéticas o contrafactuales. Es un hecho evidente que las formas de pasado (a excepción del indefinido) muy frecuentemente no aluden a situaciones reales anteriores al momento presente sino a situaciones ficticias o hipotéticas, como se observa en los ejemplos (15)-(18):

(15) Si tuviera dinero, te lo daba.

(16) Mañana venía tu padre, ¿no?

(17) ¿Tú llamarías ahora a Pedro?

(18) ¿Vale que tú eras médico y yo iba a tu casa y to pcdía ayuda? 
La forma en que concebimos estos usos desde los presupuestos de la Gramática Cognitiva hace uso de su concopción de las relaciones de categorización y tiene que ver con la forma en que Langacker (1987: 377-386) concibe la relación entre valores prototípicos y otros mús abstractos o esquemáticos. Para Langacker las categorías lingüísticas son categorías complejas típicamente polisémicas: los significados de los signos deben concebirse como redes conceptuales en las que se establecen dos tipos de conexiones entre unos nódulos y otros. Por un lado, se dan relaciones de elaboración por las que se constatan relaciones de hiperonimia / hiponimia, es decir, entre un concepto específico y otro más general y abstracto cuyas especificaciones son cumplidas exhaustivamente en el concepto específico. Esta es la relación existente entre el concepto dc árbol y los conceptos de cerezo, olivo, roble, castaño, etc. Se entiende que árbol reúne los rasgos comunes compartidos por las especies concretas de árbol. Ahora bien, en una red también se da otro tipo de relación de catcgorización a la que Langacker (ibid.) llama de extensión de uso: con este otro tipo un determinado concepto es usado para catcgorizar otro concepto que no cumple todas las cspecificaciones relevantes del primero. Ese sería el caso, por cjcmplo, si usáramos el concepto de árbol parat categorizar cl de palmera. Muchos de los rasgos que sirven para definir la categoria prototípica de árbol no se reconocen en el caso de la palmera (hojas, ramas, forma, etc.). Sin embargo, hay suficientes aspectos comparidos por la palmera y otras especies en las que reconocemos ejemplares típicos de árbol como para sancionar esa categorización. Pues bien, a partir de este nuevo vínculo, puede generarsc, en la medida en que el uso reiterado de la categorización así lo motive, un nuevo concepto de árbol, más abstracto que el anterior (árbol') y que surge a parlir de la constatación de los rasgos compartidos por el concepto de árbol previamente establecido y el de palmera. A este nuevo concepto más abstracto Langacker lo llama esquema, y manticne una relación de elaboración con los conceptos de árbol y de palmera. Estas redes, además, se suponen no sólo para las unidades léxicas sino también para las categorías gramaticales y fonológicas.

En cuanto a la cuestión que nos atañe, y en línea con la sugerencia de Taylor (1989: 149-154) sobre la relación metonímica entre valores de pasado y valores contrafactuales o irreales, podemos suponer una trama de este tipo entre los valores vinculados al pasado cronológico de los morfemas de pasado, los valores vinculados a los usos de ficción o contrafactuales, y un valor genérico o esquemático que reúne los rasgos compartidos por los otros usos más específicos y que se correspondería con la idea de 'distancia de la realidad presente' o de 'no actualidad'. En esa concepción los valores vinculados al pasado cronológico real ocuparían la posición del prototipo, los valores relativos a mundos ficticios, irreales o altcrnativos a la realidad presente actual surgirían por extensión del valor prototípico de pasado, y el valor genérico de 'no actualidad' como abstracción esquemática de los otros dos. Así se muestra en la figura 8 , donde las flechas de trazo continuo representan relaciones de elaboración y la de trazo discontinuo relación de extensión.

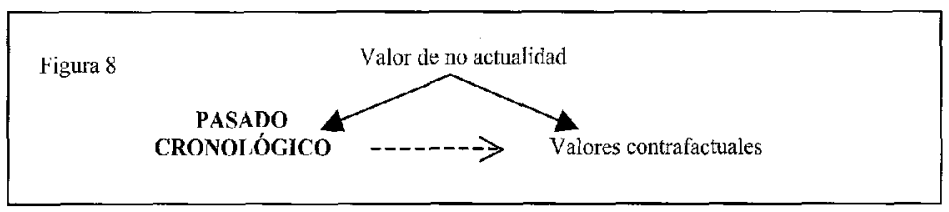


En esta configuración, aunque el valor genérico reconocible en todos los usos es el de no actualidad, el valor prototípico y central, en torno al cual se monta la red de valores, es el de pasado cronológico. Esta concepción se representa de forma más gráfica en la figura 10 . Probablemente el rasgo compartido por valores de pasado y valores contrafactuales y que justifica la extensión metonímica sea el de situaciones vigentes sólo en nuestra memoria o nuestra imaginación sin correlato con la realidad circundante, lo que intentamos representar pictóricamente con la «nube de pensamiento».

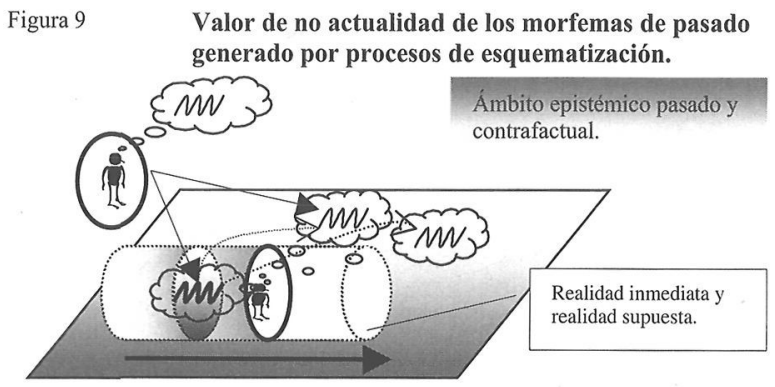

Resulta atractiva la posibilidad de reconocer, en esta forma de abordar la relación entre valores prototípicos y valores esquemáticos de los morfemas verbales, un modo de integrar las visiones alternativas que se han adoptado del sistema verbal español. Concepciones como las de Alarcos (op. cit.), donde más que de tiempos de pasado y presente se habla de perspectivas de presente y pasado, darían cuenta del nivel más abstracto de representación, mientras que visiones decididamente temporalistas, como la de Rojo y Veiga (op. cit.), entre otros, se circunscribirían al nivel de descripción de los usos prototípicos. En el marco de la gramática cognitiva, ambas visiones se acogen como descripciones correspondientes a niveles de abstracción distintos y, por tanto, pueden tener carácter complementario.

\section{RECAPITULACIÓN}

A modo de síntesis, mostramos en la figura 10 un intento de representación gráfica de los elementos comentados hasta ahora. Para interpretarla correctamente debemos tener en cuenta las convenciones gráficas de la tabla 2 .

En la figura 10 se representan, mediante figuras humanas, dos centros deícticos o puntos de referencia: uno de ellos presente y primario y otro pasado y secundario. Los espacios epistémicos que se ordenan en torno al centro deíctico primario se reproducen en torno al centro deíctico secundario. Este punto de referencia o centro deíctico secundario aparece en su localización prototípica de pasado respecto al punto de referencia primario, pero igualmente puede situarse, junto con su cohorte de zonas epistémicas, en cualquier otro ámbito de la irrealidad, lo cual permite dar cuenta de la reconstrucción de mundos ficticios o contrafactuales. Obsérvese que en el gráfico se han señalado las zonas epistémicas y temporales correspondientes a las distintas formas del sistema verbal: las formas de indicativo (cantas/has cantado; cantabas/habias cantado/cantaste) sitúan en una única región epistémica: la realidad inmediata que rodea a cada centro deíctico. Las formas de condicionado 


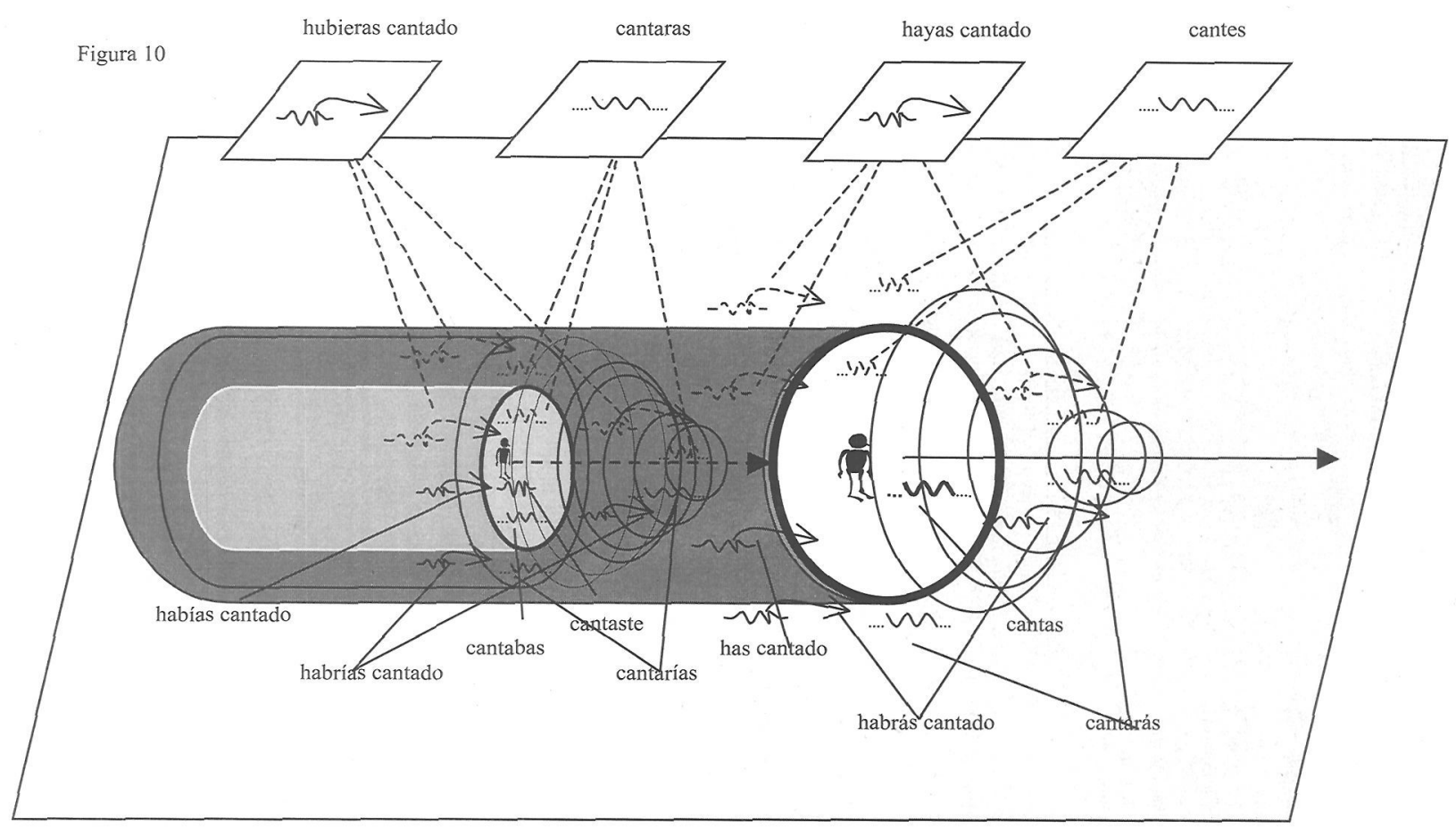




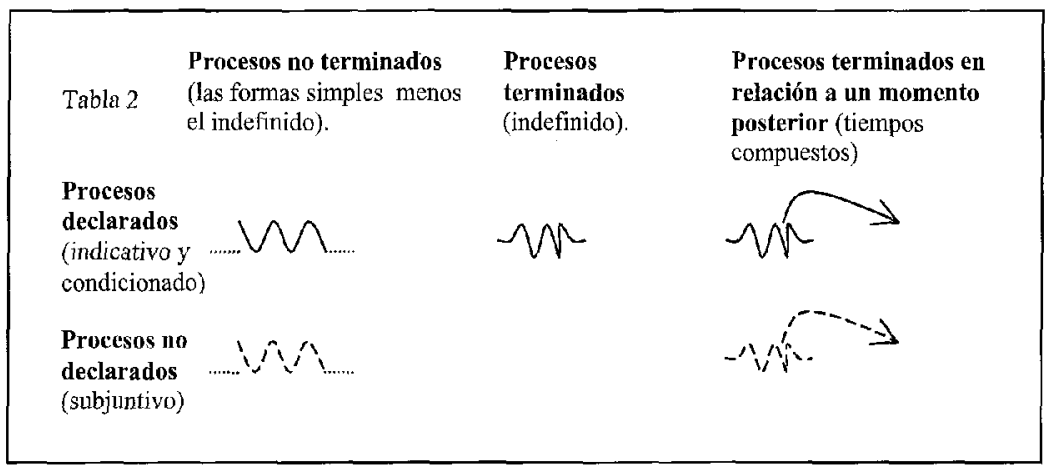

(cantarás/habrás cantado; cantarias/habrias cantado) localizan en dos zonas epistémico y temporalmente relcvantes tanto para el pasado como para el presente: la realidad supuesta contemporánea al punto de referencia y la realidad supuesta posterior al punto de referencia. Las formas de subjuntivo (cantes/hayas cantado; cantaras/hubieras cantado), por su parte, apuntan a tres regiones tanto en el pasado como en el presente: la realidad inmediata, la realidad supuesta contemporánea al punto de referencia y la realidad supuesta postcrior al punto de referencia.

En cl presente trabajo hemos esbozado algunos de los aspectos fundamentales en los que creemos que se puede basar una descripción del sistema temporal modal del verbo español inspirado en el modelo de la Gramática Cognitiva de Langacker. Entre tales conceptos ha sido fundamental la noción de modelo epistémico elaborado para la caracterización modal de las formas de condicionado, pero también han resultado especialmente relevantes la explicación perifrástica que ofrece Langacker de los valores aspectuales y temporales de los tiempos compuestos, su concepción de las funciones relativas a la determinación y la distinción entre perfil y base en la explicación del subjuntivo frente a los otros modos, así como la noción de alcance de la representación en la interpretación aspectual de la oposición imperfecto/indefinido. Creemos que, además, la descripción gcnérica del sistema verbal que aquí se presenta, tiene la ventaja, en virtud de la distinción, también propia de la Gramática Cognitiva, entre representaciones prototípicas y esquemáticas, de permitir superar las discusiones sobre el carácter básico de la temporalidad en la constitución del sistema verbal español.

\section{REFERENCIAS BIBLIOGRÁFICAS}

Alarcos Llorach, E. (1994): Gramática de la lengua españala. Madrid, Fspasa Calpe.

Borges, J. L. (1992): La penúltima versión de la realidad, discusion. obras completas, i (1923-1936) Círculo de lectores.

Castañeda, A y J. Ortega (2001): «Atención a la forma y gramática pedagógica: algunos aspcctos del metalenguaje de presentación de la oposición imperfecto/indefinido en el aula de español/LE», Estudios de Lingüistica. Universidad de Alicante, 2001, Número Monógráfico dedicado a «Tendencias y líneas de investigación en adqusición de segundas lenguas», coordinado por Susana Pastor Cesteros y Ventura Salazar García, págs 213-248. 
Grice, H. P. (1975): «Logic and conversation», en P. Cole y J. L. Morgan (eds.), Syntax and Semantics. 3. Speech Acts. New York: Academic Press (págs. 41-58). (Trad. esp.: «Lógica y conversación», en L. M. Valdés Villanueva (ed.), La búsqueda del significado. Madrid, Murcia: Tecnos, Universidad de Murcia, 1991 (págs.: 511-530).)

Langacker, R. W. (1987): Foundulions of Cognitive Grammar. Volume I: Theoretical Prerequisiles. Stanford: Stanford University Press.

Langacker, R. W. (1991): Foundations of Cognitive Grammar. Volume II: Descriptive Application. Stanford: Stanford University Press.

Rojo, G. y A. Veiga (1999): «El tiempo verbal. Los tiempos simples», en I. Bosque y V. Demonte (eds.), Gramática descriptiva de la lengua española. Vol. II. Las construcciones sintácticas fundameniales. Relaciones temporales, aspectuales y modales. Madrid, Fspasa Calpe, págs. 28672934.

Ruiz Campillo, J. P. (1998): La enseñanza significativa del sistema verbal: un modelo operativo. Universidad de Granada (tesis doctoral inédita).

Taylor, J. R. (1989): Linguistic Categorization. Prototypes in Linguistic Theory. Oxford: Oxford University Press. 